\title{
Peripheral blood myeloid-derived suppressor cells reflect disease status in idiopathic pulmonary fibrosis
}

\author{
Isis E. Fernandez ${ }^{1}$, Flavia R. Greiffo ${ }^{1}$, Marion Frankenberger ${ }^{1}$, Julia Bandres ${ }^{1}$, \\ Katharina Heinzelmann ${ }^{1}$, Claus Neurohr ${ }^{2,3}$, Rudolf Hatz ${ }^{2}$, Dominik Hartl ${ }^{4,5}$, \\ Jürgen Behr $r^{2,3}$ and Oliver Eickelberg ${ }^{1}$
}

\begin{abstract}
Affiliations: ${ }^{1}$ Comprehensive Pneumology Center, Ludwig-Maximilians-University, University Hospital Grosshadern, and Helmholtz Zentrum München, Member of the German Center for Lung Research, Munich, Germany. ${ }^{2}$ Asklepios Fachkliniken München-Gauting, Munich, Germany. ${ }^{3}$ Comprehensive Pneumology Center, Medizinische Klinik und Poliklinik V, Klinikum der Ludwig-Maximilians-Universität, Member of the German Center of Lung Research (DZL), Munich, Germany. ${ }^{4}$ Children's Hospital of the University of Tübingen, Pediatric Infectiology, Immunology and Cystic Fibrosis, Tübingen, Germany. ${ }^{5}$ Roche Pharma Research and Early Development (pRED), Immunology, Inflammation and Infectious Diseases (I3) Discovery and Translational Area, Basel, Switzerland.
\end{abstract}

Correspondence: Oliver Eickelberg, Comprehensive Pneumology Center, Ludwig-Maximilians-University and Helmholtz Zentrum München, Max-Lebsche-Platz 31, 81377 Munich, Germany.

E-mail: oliver.eickelbergahelmholtz-muenchen.de

ABSTRACT Idiopathic pulmonary fibrosis (IPF) is a fibroproliferative disease with irreversible lung function loss and poor survival. Myeloid-derived suppressor cells (MDSC) are associated with poor prognosis in cancer, facilitating immune evasion. The abundance and function of MDSC in IPF is currently unknown.

Fluorescence-activated cell sorting was performed in 170 patients (IPF: $n=69$; non-IPF interstitial lung disease (ILD): $n=56$; chronic obstructive pulmonary disease (COPD): $n=23$; healthy controls: $n=22$ ) to quantify blood MDSC and lymphocyte subtypes. MDSC abundance was correlated with lung function, MDSC localisation was performed by immunofluorescence. Peripheral blood mononuclear cell (PBMC) mRNA levels were analysed by qRT-PCR.

We detected increased MDSC in IPF and non-IPF ILD compared with controls $(30.99 \pm 15.61 \%$ versus $18.96 \pm 8.17 \%, \mathrm{p} \leqslant 0.01)$. Circulating MDSC inversely correlated with maximum vital capacity $(\mathrm{r}=-0.48$, $\mathrm{p} \leqslant 0.0001)$ in IPF, but not in COPD or non-IPF ILD. MDSC suppressed autologous T-cells. The mRNA levels of co-stimulatory $\mathrm{T}$-cell signals were significantly downregulated in IPF PBMC. Importantly, $\mathrm{CD}_{3}{ }^{+} \mathrm{CD} 11 \mathrm{~b}^{+}$cells, suggestive of MDSC, were detected in fibrotic niches of IPF lungs.

We identified increased MDSC in IPF and non-IPF ILD, suggesting that elevated MDSC may cause a blunted immune response. MDSC inversely correlate with lung function only in IPF, identifying them as potent biomarkers for disease progression. Controlling expansion and accumulation of MDSC, or blocking their T-cell suppression, represents a promising therapy in IPF.

@ERSpublications

Circulating myeloid-derived suppressor cells are increased in IPF and inversely correlate with lung function http://ow.ly/6rDm301BpvC

This article has supplementary material available from erj.ersjournals.com

Received: Nov 042015 | Accepted after revision: June 152016 | First published online: Sept 012016

Support statement: This work was supported by the Helmholtz Association and the German Center for Lung Research. Funding information for this article has been deposited with the Open Funder Registry.

Conflict of interest: Disclosures can be found alongside this article at erj.ersjournals.com

Copyright @ERS 2016 


\section{Introduction}

Idiopathic pulmonary fibrosis (IPF) is a chronic and lethal fibroproliferative disease of the lung, with unknown aetiology. IPF is characterised by an irreversible loss of lung function with a median survival, or time to lung transplantation, of 2-3 years after diagnosis. The natural history of IPF is highly variable and unpredictable between patients [1]. In the past years, many advances have been accomplished with respect to better delineating dominant pathomechanisms and improved diagnosis, monitoring or treatment of IPF. These efforts have led to the approval of two new therapeutics, pirfenidone and nintedanib, which slow down lung function decline in IPF [2].

While the exact pathophysiology of IPF remains unknown, several key drivers of disease initiation and progression have been unravelled, including repetitive microinjuries to the bronchial and alveolar epithelium [3], aberrantly activated fibroblast phenotypes, and excessive extracellular matrix (ECM) accumulation [4]. While nonspecific immunosuppressive therapy remained without benefit in a number of clinical studies, recent findings of gene expression signatures and peripheral blood biomarker profiling have highlighted the possibility of immune system dysfunction in IPF pathogenesis (e.g. correlating gene expression levels with B- and T-cell activation [5-8]).

Importantly, innate and adaptive immunity contributes to fibrogenesis in a number of organs [9]. The recent literature has provided increasing evidence for a pro-inflammatory signature in peripheral blood and lung tissue of IPF patients, including aberrantly activated lymphocyte/monocyte populations [10]. In IPF, circulating leukocyte phenotypes, for instance $\mathrm{CD}^{+}$T-cells, display reduced levels of CD28, suggesting persistent antigen-driven proliferation and possibly clonal exhaustion [6]. These data are supported by recent transcriptome analysis of peripheral blood mononuclear cells (PBMCs) in which the co-stimulatory T-cell signal (assessed by mRNA levels of CD28, ICOS, LCK and ITK) was downregulated and predicted poorer survival in IPF patients [7]. Semaphorin (Sema) 7a-positive T-regulatory (T-reg) cells are increased in rapidly progressive IPF patients [5], thus supporting the role of dysregulated T-cell responses in IPF.

Myeloid-derived suppressor cells (MDSCs) are a heterogeneous population of immature myeloid cells with potent suppressor capabilities, which are associated with poor prognosis in cancer [11]. MDSCs contribute to tumour-immune cell evasion by suppressing T-cell responses [12]. Currently, MDSCs are not classified by a standard leukocyte lineage marker, since MDSCs are comprised of various immature cells of myeloid origin, including myeloid-progenitor cells, immature monocytes or dendritic cells, or immature granulocytes. Two important subsets of human MDSCs have been reported: monocytic MDSC

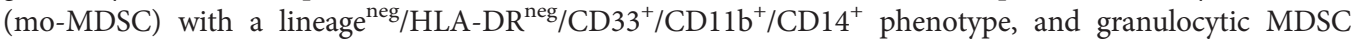
(g-MDSC) with a lineage $e^{\text {neg }} / \mathrm{HLA}-\mathrm{DR}{ }^{\text {neg }} / \mathrm{CD} 33^{+} / \mathrm{CD} 11 \mathrm{~b}^{+} / \mathrm{CD} 14^{-} / \mathrm{CD} 15^{+} / \mathrm{CD}_{6} 6 \mathrm{~b}^{+}$phenotype [13]. The accumulation of MDSCs is a common finding in malignancies, including lung cancer, but also in many other pathological conditions, such as transplantation [14], infection [15] or autoimmunity [16]. In nonsmall cell lung cancer, patients with higher amounts of peripheral MDSCs had poorer survival or response to chemotherapy [17]. In chronic inflammatory processes of the lung, such as tuberculosis (TB) [18] or Pseudomonas aeruginosa infection secondary to cystic fibrosis [19], MDSCs induce T-cell suppression to avoid immune surveillance and undermine host defence. In COPD, a suppressive network comprised by T-reg cells, PD- $1^{+}$T-cells and MDSCs counteract the inflammatory immune reaction and mitigate innate antibacterial and antiviral properties [20]

Importantly, the contribution of MDSCs in fibrotic lung disease, including IPF, has not been elucidated at all to date [21]. Therefore, in this study we performed, for the first time, an in-depth characterisation of MDSCs in the peripheral blood and lung tissue of IPF patients and correlated their levels with parameters of disease severity. Intriguingly, MDSCs inversely correlate with lung function and can be detected in lung tissue of IPF patients, highlighting their potential contribution to IPF pathogenesis.

\section{Materials and methods}

For in-depth details on the material and methods, refer to the supplementary material.

\section{Patients and control group}

We prospectively included 170 patients in the analysis, divided into 69 IPF, 56 non-IPF ILD (hypersensitivity pneumonitis: $n=17$, nonspecific interstitial pneumonia: $n=27$, connective tissue disease-ILD: $n=12$ ) and 23 COPD patients, as well as 22 healthy controls. Patients were recruited at the Comprehensive Pneumology Center (Munich, Germany) from June 2014 to July 2015 (table 1). 22 healthy volunteers (table 1) were free from signs of current infection, inflammation or respiratory symptoms at the time of blood sampling. Informed written consent was obtained for all participants, study methods were approved by the local ethical review board. Diagnosis of IPF was performed by multidisciplinary consensus, based on current American Thoracic Society/European Respiratory Society criteria [22]. 


\begin{tabular}{|c|c|c|c|c|}
\hline Characteristics & Control & IPF & Non-IPF ILD & COPD \\
\hline Subjects & 22 & 69 & 56 & 23 \\
\hline Age years & $55.4 \pm 6.4$ & $68.2 \pm 11.1^{* *}$ & $62.5 \pm 10.4^{*}$ & $58.3 \pm 6.4$ \\
\hline \multicolumn{5}{|l|}{ Sex } \\
\hline Male & $11(50 \%)$ & $55(79.7 \%)$ & $30(53.5 \%)$ & $11(47.8 \%)$ \\
\hline Female & $11(50 \%)$ & $14(20.2 \%)$ & $26(46.4 \%)$ & $12(52.1 \%)$ \\
\hline \multicolumn{5}{|l|}{ ILD type } \\
\hline CTD-ILD & & & $12(21.4 \%)$ & \\
\hline $\mathrm{HP}$ & & & $17(30.3 \%)$ & \\
\hline NSIP & & & $27(48.2 \%)$ & \\
\hline \multicolumn{5}{|l|}{ Smoking status ${ }^{\#}$} \\
\hline Current & $5(22.7 \%)$ & $5(7.2 \%)$ & 0 & $1(4.3 \%)$ \\
\hline Former & $6(27.2 \%)$ & $40(57.9 \%)$ & $26(46.4 \%)$ & $22(95.6 \%)$ \\
\hline Nonsmokers & $11(50 \%)$ & $24(34.7 \%)$ & $30(53.6 \%)$ & 0 \\
\hline DLco \% pred & & $33.8 \pm 16.7$ & $32.5 \pm 16.3$ & $25.3 \pm 18.7$ \\
\hline VCmax \% pred & & $61.6 \pm 17.8$ & $61.3 \pm 19.2$ & $61.1 \pm 26.6$ \\
\hline \multicolumn{5}{|c|}{$\begin{array}{l}\text { Data are presented mean } \pm S D \text {, unless otherwise stated. IPF: idiopathic pulmonary fibrosis; ILD: interstitial } \\
\text { lung disease; COPD: chronic obstructive pulmonary disease; CTD: connective tissue disease; HP: } \\
\text { hypersensitivity pneumonitis; NSIP: nonspecific interstitial pneumonia; } D \text { LCO: diffusing capacity of the lung } \\
\text { for carbon monoxide; } V C \text { max: maximum vital capacity. }{ }^{*} \text { : subjects with } \geqslant 5 \text { pack-years of cigarette smoking. } \\
{ }^{*}: p<0.05 \text { versus healthy controls; }{ }^{* *}: p<0.01 \text { versus healthy controls. }\end{array}$} \\
\hline
\end{tabular}

\section{Cell isolation and flow cytometry analysis}

For immunophenotyping, fresh venous blood was collected in EDTA-coated vacutainer tubes (Sarstedt, Nümbrecht, Germany). Briefly, whole blood or PBMC buffy coats were used for flow cytometry detection of MDSC and lymphocyte subtypes. MDSC were gated as lineage ${ }^{\text {neg }} / \mathrm{HLA}-\mathrm{DR}{ }^{\text {neg }} / \mathrm{CD} 33^{++} / \mathrm{CD} 11 \mathrm{~b}^{+} / \mathrm{CD} 14^{+}$ or lineage $e^{\text {neg }} / \mathrm{HLA}-\mathrm{DR}^{\text {neg }} / \mathrm{CD} 33^{+} / \mathrm{CD} 11 \mathrm{~b}^{+} / \mathrm{CD} 6 \mathrm{~b}^{+}$, and data presented as $\%$ gated HLA-DR ${ }^{\text {neg }}$ cells. $\%$ mo-MDSC and \%g-MDSC was determined and presented as $\%$ gated $\mathrm{CD}_{3} 3^{++} \mathrm{CD}_{11 \mathrm{~b}^{+}}$and $\mathrm{CD} 33^{+}$ $\mathrm{CD}_{11} \mathrm{~b}^{+}$, respectively. Lymphocyte subtypes were determined as T-cells $\left(\mathrm{CD}^{+}\right)$, T-helper $\left(\mathrm{CD} 3^{+} \mathrm{CD} 4^{+}\right)$ (effector $\left(\mathrm{CCR} 7^{-}\right)$and non-effector $\left(\mathrm{CCR} 7^{+}\right)$), T-cytotoxic $\left(\mathrm{CD}^{+} \mathrm{CD}^{+}\right)$(effector $\left(\mathrm{CCR}^{-}\right)$and non-effector $\left.\left(\mathrm{CCR} 7^{+}\right)\right)$, abnormal T-cells $\left(\mathrm{CD}^{+} \mathrm{CD} 4^{+} \mathrm{CD} 8^{+}\right)$and $\mathrm{T}$-reg cells $\left(\mathrm{CD} 4^{+} \mathrm{CD} 25^{+}\right.$and $\mathrm{CD} 4^{+} \mathrm{CD} 25^{+} \mathrm{FoxP}^{+}$), with the antibody list detailed in figure $\mathrm{E} 1$ and table E1, as previously reported [23]. For whole blood staining, $100 \mu \mathrm{L}$ was incubated with an antibody mix for MDSC (table E1) for $20 \mathrm{~min}$ at $4^{\circ} \mathrm{C}$ in the dark. Erythrocytes were lysed with a Coulter Q-Prep working station (Beckman Coulter, Germany), as previously reported [24]. For lymphocyte analysis, PBMCs were prepared from blood samples using density gradient sedimentation (Lymphoprep; STEMCELL Technologies, Cologne, Germany). Trypan blue staining was used for differentiation between viable and nonviable cells, and showed viability of $>90 \%$ for all cells used in this study. After gradient separation, cells were stained with lymphocyte antibody mix for $20 \mathrm{~min}$ at $4^{\circ} \mathrm{C}$ in the dark. Data acquisition was performed in a BD LSRII flow cytometer or a BD fluorescence-activated cell sorter (FACS) ARIA II (both Becton Dickinson, Heidelberg, Germany) if cells were sorted. Data was analysed with FlowJo software (TreeStart Inc, Ashland, OR, USA). Negative thresholds for gating were set according to isotype-labelled controls.

\section{T-cell suppression assay and MDSC co-culture}

The T-cell suppression assay and MDSC co-cultures were performed as previously published [19, 25]. Briefly, PBMCs from IPF patients were isolated, stained with CFSE (CellTrace, C34554; ThermoFisher Scientific, Darmstadt, Germany) and stimulated with recombinant human IL-2 (100 U.mL $\mathrm{mL}^{-1}$ BD Pharmingen, San Diego, CA, USA) and OKT3 (1 $\mu \mathrm{g} \cdot \mathrm{mL}^{-1}$; Biolegend, San Diego, CA, USA). PBMCs were incubated with stimulation media alone or with isolated autologous MDSC. After 4 days, cells were harvested and stained with anti-CD4-PE or anti-CD8-allophycocyanin (Biolegend). CSFE fluorescence intensity of each cell type was analysed by flow cytometry. The percentage of proliferation was analysed for $\mathrm{CD}^{+}$and $\mathrm{CD}^{+}$cells cultured alone or in conjunction with MDSC. Data were analysed with FlowJo software. After $96 \mathrm{~h}$ of incubation, cells were harvested and stained with anti-CD4-PE (BD Pharmingen) and anti-CD8-allophycocyanin. CFSE fluorescence intensity was analysed by flow cytometry to determine proliferation of $\mathrm{CD}^{+}$and $\mathrm{CD}^{+}$T-cells. After $96 \mathrm{~h}$ of incubation, cells were harvested and stained with anti-CD4-PE (BD Pharmingen) and anti-CD8-allophycocyanin. CFSE fluorescence intensity was analysed by flow cytometry to determine proliferation of $\mathrm{CD} 4^{+}$and $\mathrm{CD} 8^{+} \mathrm{T}$-cells. 


\section{Statistical analysis}

Data are presented as scatter plots with mean \pm SD. Two group comparisons were made using a non-parametric two-tailed Mann-Whitney U-test, parametric test or paired t-test, when specified. Three or more group comparisons were made using one-way ANOVA, with the non-parametric Kruskal-Wallis test followed by Dunnett's test. Associations between variables were established by linear regression and Pearson correlation. GraphPad Prism (version 5.0; GraphPad Software, San Diego, CA, USA) was used for statistical analyses. Significance was defined as $\mathrm{p}<0.05$.

\section{Results}

Patient demographics

In total, 170 patients and controls were included in this study (table 1). From those, 69 were diagnosed with IPF, 56 with non-IPF ILD (connective tissue disease-ILD: $n=12$, hypersensitivity pneumonitis: $n=17$; nonspecific interstitial pneumonia: $\mathrm{n}=27$ ) and 23 with COPD, and 22 were healthy controls. Patient demographics are shown in table 1.

\section{MDSC are increased in the peripheral blood of patients with lung fibrosis}

Whole blood MDSC (defined as lineage ${ }^{\text {neg }} / \mathrm{HLA}-\mathrm{DR}{ }^{\text {neg }} / \mathrm{CD} 33^{+} / \mathrm{CD} 11 \mathrm{~b}^{+}$cells) were measured and quantified in freshly drawn blood in all study subjects. Previous reports in several types of cancer [11] or lung disorders have described human circulating MDSCs as monocytic $\left(\mathrm{CD} 14^{+}\right)$or granulocytic $\left(\mathrm{CD}_{6} 6 \mathrm{~b}^{+}\right)$ [13]. In order to set a threshold for positive-negative discrimination, a fluorescently labelled isotype was used as a control for each subject (figure 1a). To exclude definitive differentiated and mature cell populations, a cocktail with lineage-definitive markers was used and positive cells were excluded (figure 1a). This was followed by exclusion of HLA-DR-positive cells and further gating on CD33 and CD11b positivity. Two distinct populations were observed: a $\mathrm{CD} 33^{++} / \mathrm{CD}_{11} \mathrm{~b}^{+}$, characterised by strong $\mathrm{CD} 14$ expression and monocytic morphology; and a $\mathrm{CD} 33^{+} / \mathrm{CD}_{11} \mathrm{~b}^{+}$, characterised by strong CD66b expression and granulocytic morphology (figure 1). We used FACS-sorted monocytic and granulocytic MDSCs to confirm their morphology using cytospins with Diff-quick staining, as well as co-expression of CD33 and CD11b by immunofluorescence staining (figure $1 \mathrm{~b}$ ).

Next, we quantified the abundance of MDSCs (as \% gated of HLA-DR ${ }^{\text {neg }}$ cells) in all subjects. We observed that the amount of MDSCs was significantly elevated in the peripheral blood of IPF $(30.99 \pm 15.61 \%, \mathrm{p}<0.01)$ and non-IPF ILD patients $(31.63 \pm 15.61 \%, \mathrm{p}<0.05)$ when compared with controls $(18.96 \pm 8.17 \%)$ or COPD $(25.63 \pm 13.94 \%, \mathrm{p}=\mathrm{NS})$ (figure $2 \mathrm{a})$. Next, to determine which MDSC phenotype was prevalent in IPF patients, we quantified the proportion of mo-MDSC (as \% gated CD $33^{++} \mathrm{CD}_{11 b^{+}}$cells) and g-MDSC (as \% gated $\mathrm{CD}_{3} 3^{+} \mathrm{CD} 11 \mathrm{~b}^{+}$cells). Interestingly, we observed that the proportion of mo-MDSC was significantly increased in IPF compared with controls (figure 2b). Inversely, the proportion of g-MDSC was significantly decreased (figure $2 \mathrm{c}$ ).

\section{Increased MDSC abundance reflects poor lung function specifically in IPF patients}

To elucidate the clinical relevance of increased circulating MDSCs, we analysed whether higher numbers of MDSCs correlated with physiological parameters that determine disease status, such as lung function. We observed that, in a cross-sectional analysis, higher numbers of peripheral blood MDSCs inversely correlated with maximum vital capacity (VCmax \% predicted) $(\mathrm{p}<0.0001, \mathrm{r}=-0.48)$ in IPF. The MDSC-VCmax correlation remained significant when all patients were pooled together, albeit with a less stringent correlation coefficient $(\mathrm{p}=0.0027, \mathrm{r}=-0.24)$ (figure 3$)$. Correlation analysis was also performed for non-IPF ILD and COPD, but no significant correlation was found for these groups $(p=0.5, r=-0.07$ and $\mathrm{p}=0.5, \mathrm{r}=-0.14$, respectively).

Although our study was not designed as a prospective longitudinal study, a number of patient revisits occurred in the study period; thus, we were able to analyse the relationship between the change in MDSC and VCmax over time in the same patients. As depicted in figure 4, 27 patients were assessed by follow-up analysis (IPF: $n=14$, non-IPF ILD: $n=11$, COPD: $n=2$ ). While the initial values are included in all patients' analysis (figure 2), we performed an additional analysis for repeat visits by correlating the delta $(\Delta)$ MDSC with $\Delta \mathrm{VCmax} \%$ predicted $(\Delta=\mathrm{V} 2-\mathrm{V} 1)$. By using this calculation, we could uncover whether the number of MDSCs changed with declining lung function over time. When patients were analysed altogether a nonsignificant weak negative correlation was observed ( $\mathrm{r}=0.09189)$ (figure $4 \mathrm{a})$. When we analysed only IPF patients, a strong and significant correlation was observed $(r=-0.5773, p=0.0389)$ (figure $4 \mathrm{~b})$.

\section{MDSC from IPF patients effectively suppress T-cell proliferation}

To confirm that peripheral blood MDSCs from IPF patients suppressed T-cell proliferation, we isolated and co-cultured PBMCs with autologous MDSCs, and assessed the suppressive function of MDSC in vitro. PBMCs were isolated (non-IPF ILD: $n=5$, IPF: $n=4$ ), stained with CFSE and cultured over a period of 
a)
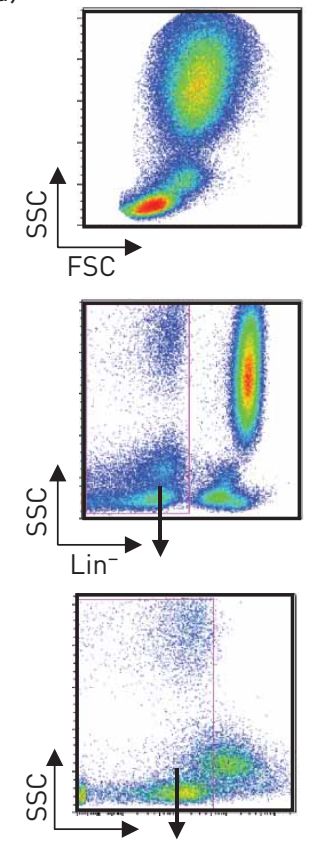

$\mathrm{HLA}^{-\mathrm{DR}^{-}}$

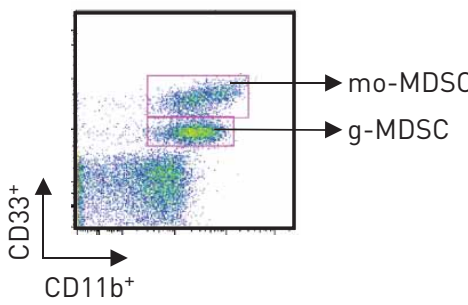

b)
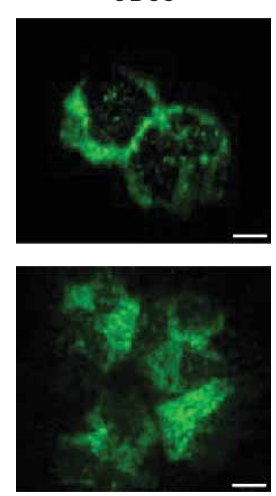

$\mathrm{CD} 11 \mathrm{~b}$
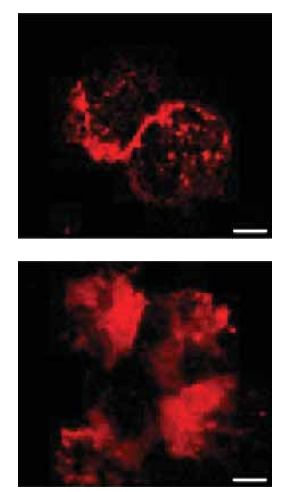

Merged
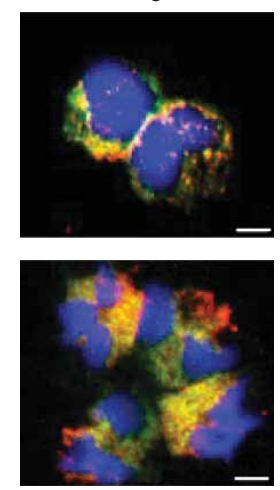
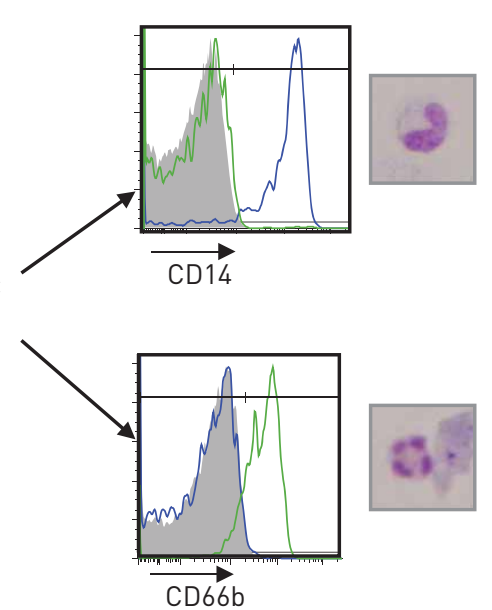

FIGURE 1 Characterisation of human myeloid-derived suppressor cells (MDSC) in whole blood. Representative dot-plots of whole blood flow cytometry analysis after red blood cell lysis. a) Cells were stained with a panel of monoclonal antibody and gated on Lin ${ }^{\text {neg }}$, HLA-DR $^{\text {neg }}$ CD33 $^{+}$

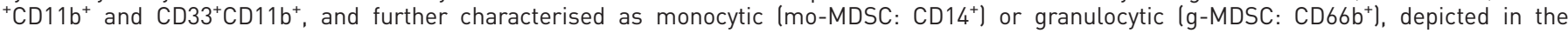
histograms as blue and green, respectively. Gates were based on isotype-stained samples, represented as grey in the histograms. Microscopic analysis of Diff-quick stained cytospins of fluorescence-activated cell sorter (FACS)-sorted mo-MDSC and g-MDSC confirmed phenotypic characteristics. b) Immunofluorescence staining of FACS-sorted mo-MDSC (top) and g-MDSC (bottom) are depicted as single channels (CD33 in green; CD11b in red) and merged channels confirmed the co-expression of MDSC markers. Scale bars=5 $\mu \mathrm{m}$. SSC: side-scattered light; FSC: forward-scattered light; HLA-DR: human leukocyte antigen-DR.

4 days. $\mathrm{CD}^{+}$and $\mathrm{CD}^{+}$T-cells showed a baseline proliferation of $70.61 \pm 18.73 \%$ and $83.69 \pm 7.68 \%$, respectively, when cultured alone in stimulation media. When autologous MDSCs were added to these cultures, at a ratio of 1:4 ( $\mathrm{T}$ cell:MDSC), $\mathrm{CD} 4^{+}$and $\mathrm{CD} 8^{+} \mathrm{T}$-cell proliferation were significantly decreased, confirming MDSC suppressive functions (figure $5 \mathrm{a}$ and $\mathrm{b}$ ).

\section{Patients with IPF exhibit elevated levels of immunosuppressive lymphocytes}

Next, we analysed lymphocyte subtypes in all subjects to test the hypothesis that an MDSC-lymphocyte axis might contribute to the immunosuppressive network in IPF. We did not observe significant differences in several T-cell subsets, including T-helper (effector and non-effector) or T-cytotoxic (effector and non-effector) cells (figure E3). However, a significant decrease in abnormal T-cells $\left(\mathrm{CD} 3^{+} \mathrm{CD} 4^{+} \mathrm{CD} 8^{+}\right.$) was observed in non-IPF ILD $(1.36 \pm 1.3 \%$ versus $3.14 \pm 2.8 \%, \mathrm{p}=0.0079)$ when compared with controls (figure E3). When we analysed $\mathrm{CD} 4{ }^{+} \mathrm{CD} 25^{+}$cells, a population that includes T-reg cells, we observed a significant increase in IPF $(52.96 \pm 21 \%, \mathrm{p}=0.0002)$ and non-IPF ILD $(55.78 \pm 19.8 \%, \mathrm{p}=0.0002)$ when compared with controls $(32.8 \pm 17.7 \%$ ) (figure 6a). We performed intracellular FoxP3 staining in lymphocytes of 26 IPF patients to determine T-reg cell abundance and correlated the percentage of T-reg cells with MDSCs. A significant positive correlation between T-reg cells and MDSCs was observed ( $\mathrm{p}=0.0484, \mathrm{r}=0.3326)$ (figure 6b). To substantiate this, we isolated PBMC mRNA of IPF patients with $>40 \%$ MDSCs and performed 

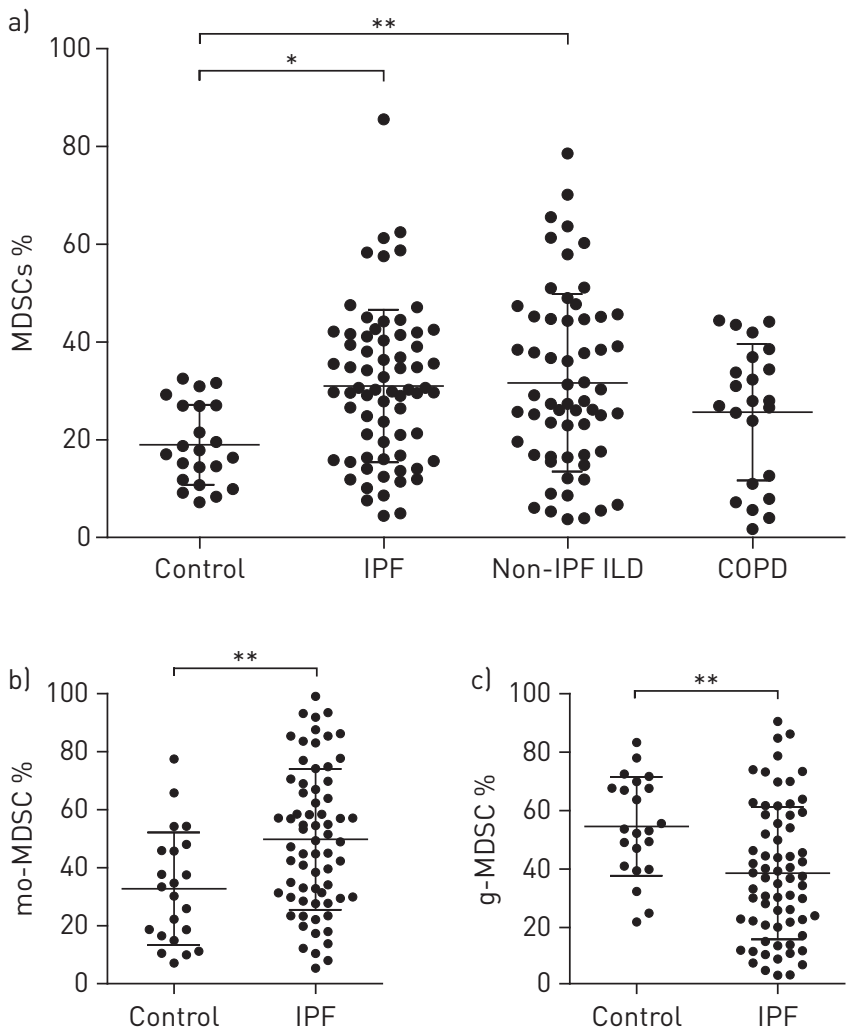

FIGURE 2 Increased abundance of myeloid-derived suppressor cells (MDSC) in lung fibrosis. a) Scatter-plot diagrams from flow cytometry analysis of MDSC counts, as \% gated HLA-DR ${ }^{\text {neg }}$ cells in 22 healthy controls, 69 idiopathic pulmonary fibrosis (IPF), 56 non-IPF interstitial lung disease (ILD) and 23 chronic obstructive pulmonary disease (COPD) patients. b) Monocytic (mo)-MDSC as \% gated $\mathrm{CD}^{2} 3^{++} \mathrm{CD} 11 \mathrm{~b}^{+}$and c) granulocytic (g)-MDSC as \% gated $\mathrm{CD} 33^{+} \mathrm{CD} 11 \mathrm{~b}^{+}$cells in 22 controls and 69 IPF patients. For statistical analysis, one-way ANOVA with the non-parametric Kruskal-Wallis test, followed by Dunnett's multiple comparison test (a), and non-parametric two-tailed Mann-Whitney $U$-test $(b, c)$ was used. ${ }^{*}: p<0.05$ versus healthy controls; ${ }^{* *}: p<0.01$ versus healthy controls. HLA-DR: human leukocyte antigen-DR.

qPCR analysis for a set of four genes that were recently related to T-cell co-stimulatory signals [7]. Importantly, the mRNA transcripts of CD28, ICOS, ITK and LCK were significantly decreased in IPF patients with high circulating MDSCs when compared with controls (figure 6c).

\section{MDSC are detected in the lungs of IPF patients}

To date, tissue-infiltrating MDSCs have been described in several human cancer types, where they have been shown to differentiate, for example, into immunosuppressive tumour-associated macrophages or dendritic cells $[26,27]$. To determine whether MDSCs are present in the fibrotic lung, we investigated lung tissue from explants of fibrotic patients (IPF and chronic hypersensitivity pneumonitis) for the presence of $\mathrm{CD}_{3}{ }^{+} \mathrm{CD} 11 \mathrm{~b}^{+}$positive cells. Sequential immunofluorescence stains from fibrotic lung tissues revealed that $\mathrm{CD} 33^{+} \mathrm{CD} 11 \mathrm{~b}^{+}$double-positive cells, suggestive of MDSC, are present in collagen 1-positive areas and neighbouring $\alpha$-SMA-positive areas in the fibrotic lung parenchyma outside vessels (figure 7).

\section{Discussion}

Our study demonstrates, for the first time, an increased abundance of circulating and tissue-infiltrating MDSCs in patients with IPF and non-IPF ILD. Specifically in IPF, MDSC abundance in the peripheral blood inversely correlates with lung function. We further detected a suppressive function in IPF MDSCs, along with an increase in circulating $\mathrm{CD} 4{ }^{+} \mathrm{CD} 25^{+}$activated T-cells, a correlation between MDSCs and FoxP3-positive T-reg cells, and a decrease in the transcript levels of CD28, ICOS, ITK and LCK in PBMCs. In our opinion, these are remarkable observations due to the following reasons. First, these data strongly support a role for an immunosuppressive environment in the peripheral blood and lungs of IPF patients. Secondly, the tight correlation of increased MDSCs with decreased lung function suggest that MDSCs, at least in part, contribute to disease progression in IPF, which is further substantiated by longitudinal assessments of $\triangle \mathrm{MDSC}$ and $\triangle \mathrm{VC}$ max $\%$ pred over time in selected patients. Thirdly, MDSC 
a)

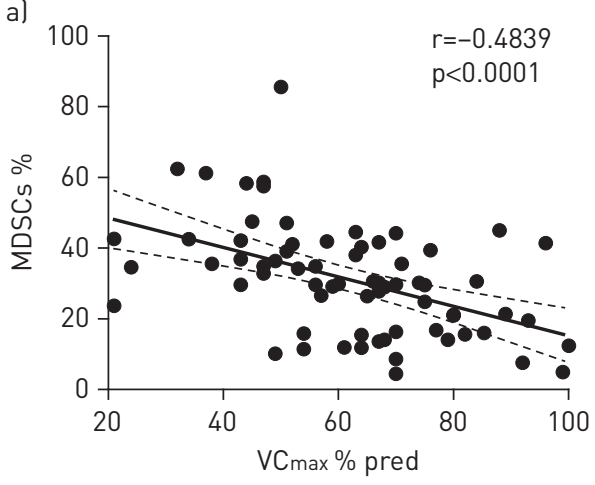

c)

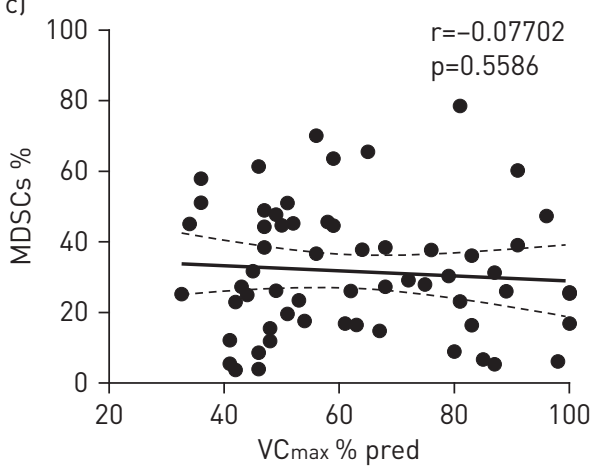

b)

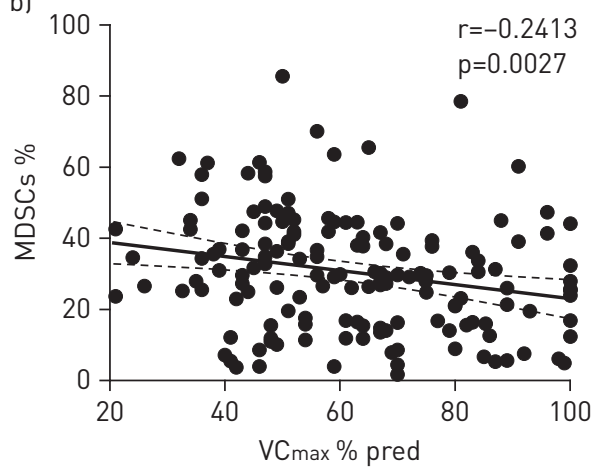

d)

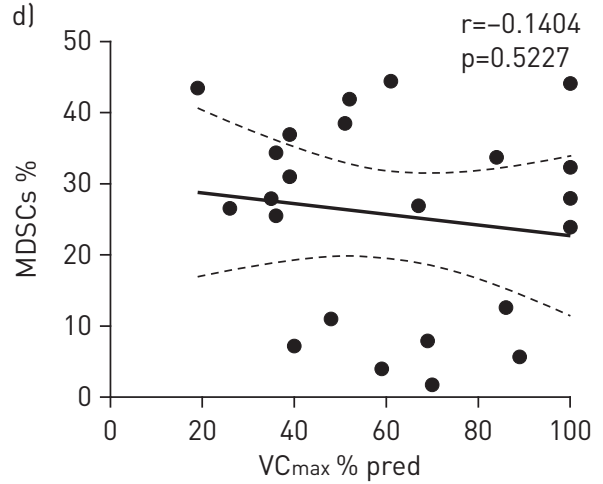

FIGURE 3 Myeloid-derived suppressor cells (MDSC) abundance inversely correlates with maximum vital capacity (VCmax) \% predicted in idiopathic pulmonary fibrosis (IPF). The percentage of gated MDSC las \% gated HLA-DR ${ }^{\text {neg }}$ cells) was inversely correlated with $\mathrm{VC}_{\max }$, as \% predicted values in a) IPF, b) all subjects, c) non-IPF interstitial lung disease and d) chronic obstructive pulmonary disease. p-values were determined by t-distribution for Pearson correlation.

abundance and/or function are currently manipulated in cancer trials. Targeting MDSC abundance and/or function may, therefore, represent an exciting novel treatment approach in IPF. Altogether, these data reveal that MDSCs are part of an immune-deregulated environment and reflect disease status in IPF.

In recent years, it has become apparent that immune dysregulation is a key contributor to fibrogenesis in a number of organs. The innate and adaptive immune system can enhance the secretion of pro-fibrotic
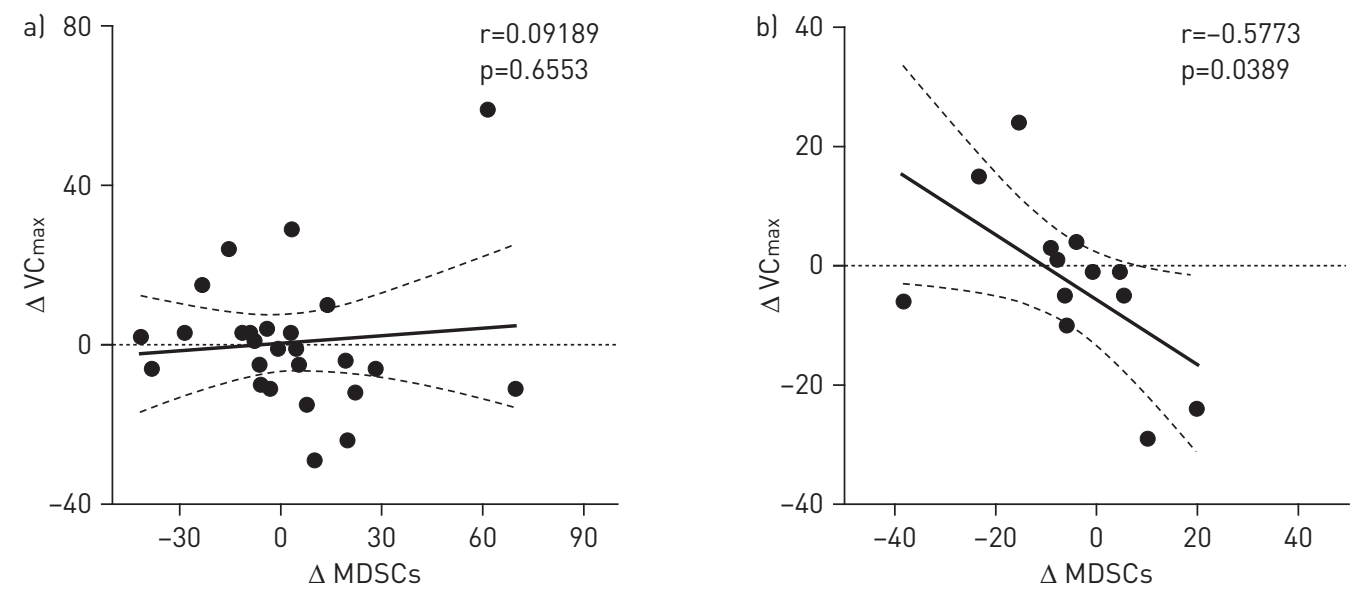

FIGURE 4 Follow-up analysis reveals correlation of myeloid-derived suppressor cells (MDSC) abundance with the disease course of idiopathic pulmonary fibrosis (IPF). $\Delta \%$ gated MDSC and maximum vital capacity (VCmax) \% predicted was calculated for patients with consecutive visits for a) all diagnosis ( $n=27$ ) and b) IPF only $(n=14)$. The $\triangle V C \max$ and $\triangle M D S C$, calculated from visit 1 to 2 , were correlated. $p$-values were determined by t-distribution for Pearson correlation. 
a)

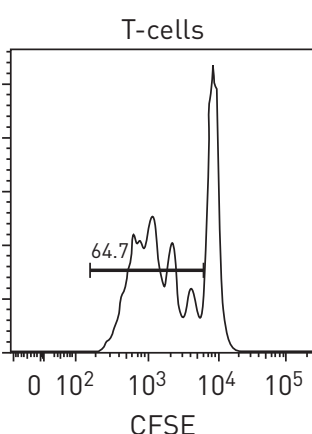

b)

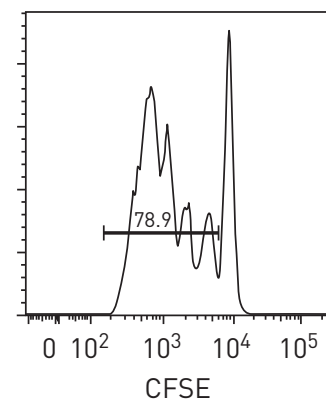

MDSCs + T-cells
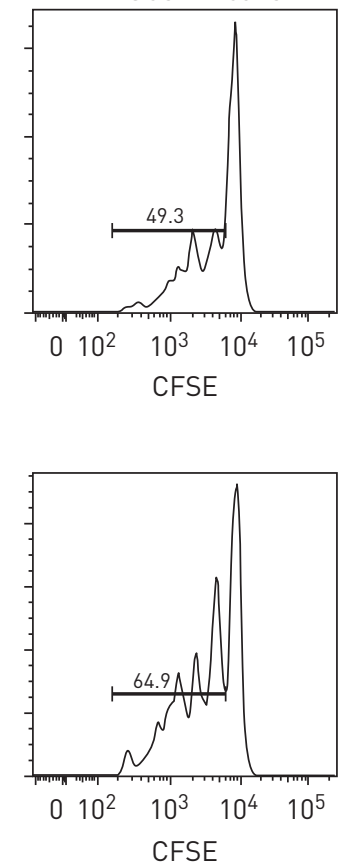

c)

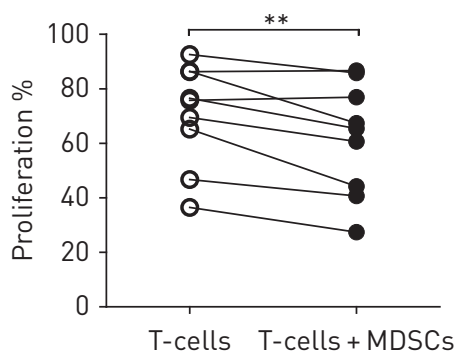

e)

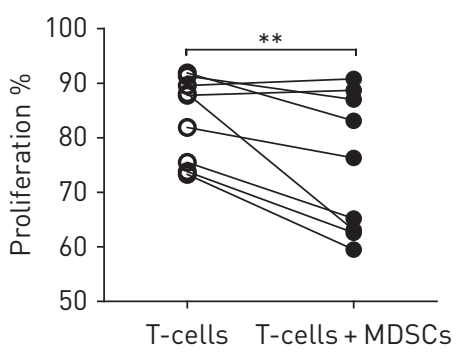

d)

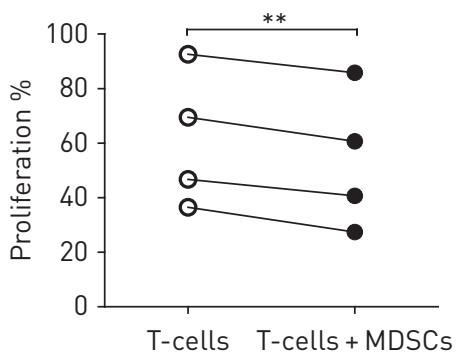

f)

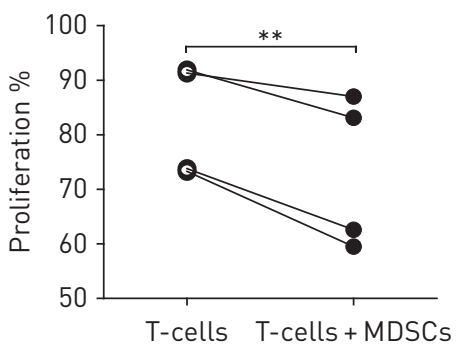

FIGURE 5 Myeloid-derived suppressor cells (MDSC) suppress autologous T-cell proliferation in idiopathic pulmonary fibrosis. Representative histogram of a) $\mathrm{CD4}^{+}$and b) $\mathrm{CD} 8^{+} \mathrm{T}$-cell proliferation, assessed by carboxyfluorescein succinimidyl ester (CFSE) incorporation and measured by flow cytometry, with medium only (left-hand panels) and co-cultured with autologous MDSC (right-hand panels). Quantification of \% proliferation of $c, d$ ) $C D 4^{+}$and e, f) $C D 8^{+}$T-cells alone or in co-culture with autologous MDSC for all patients ( $n=9$ ) (c, e) or idiopathic pulmonary fibrosis only $(n=4)(d, f)$. For statistical analysis paired t-tests were used. ${ }^{* *}: p<0.01$.

factors that direct the healing/scarring response towards a fibrotic outcome [9]. Historically, harmful effects of global immunosuppressive therapy in IPF (e.g. by using prednisone and/or azathioprine) outweighed this possibility, as a randomised controlled trial reported an increased mortality in IPF patients subjected to anti-inflammatory therapy [28]. Herein, we provide compelling evidence for the observation that IPF patients exhibit an immunosuppressive network in the peripheral blood and lungs, driven by MDSCs. Taking this into account, traditional immunosuppressive therapies would, instead, perpetuate the already dysregulated immune environment and be deleterious for disease.

A growing body of literature supports a role for T-cells in IPF pathogenesis [29]. MARCHAL-SOMmÉ et al. [30] reported ectopic formation of secondary lymphoid tissue in fibrotic niches of IPF lungs, supporting enhanced migration and generation of activated T- and B-cell subtypes in IPF. Although several subtypes of activated T-cells have been associated with progression and outcome in IPF, the literature remains controversial to date. Recently, GILANI et al. [6] showed that $\mathrm{CD}^{+}$T-cells displayed a marked downregulation in the surface expression of CD28 in IPF, which was associated with worse outcome. The CD4 ${ }^{+} \mathrm{CD} 28^{-} \mathrm{T}$-cells detected in this study showed a decrease in CD25 and FoxP3 expression. Nonetheless, $\mathrm{CD} 4^{+} \mathrm{CD} 25^{+} \mathrm{FoxP} 3^{+}$total numbers (non-discriminated by CD28) were not reported in this study. Furthermore, KoTSIANIDIs et al. [8] reported that peripheral blood and BAL T-reg cells $\left(\mathrm{CD} 4^{+} \mathrm{CD} 25^{+} \mathrm{FoxP} 3^{+}\right)$were decreased in IPF. Importantly, the identification of T-reg subsets in fibrotic conditions of the human lung is more discriminative when $\mathrm{CD}^{+} / \mathrm{CD} 25^{+} / \mathrm{CD} 27^{+}$cells are assessed [31]. Recently, Sema $7 \mathrm{a}^{+} / \mathrm{CD} 4^{+} / \mathrm{CD} 25^{+} / \mathrm{FoxP}^{+}$cells were found to be increased in rapidly progressive IPF patients, and adoptive transfer of these cells to transforming growth factor- $\beta$ overexpressing mice was sufficient to induce fibrosis [5], corroborating the notion that increased T-reg cells induce and/or facilitate fibrogenesis in the lung. In other animal models of fibrosis, depletion of $\mathrm{CD}^{+} \mathrm{CD} 25^{+} \mathrm{FoxP}^{+}$cells by administration of a blocking CD25 antibody switched T-helper 2-driven responses towards a T-helper 1 kind and attenuated fibrosis development [32].

Importantly, extensive gene expression profiling in the peripheral blood of IPF patients has recently extended this knowledge. YANG et al. [33] first demonstrated that the peripheral blood transcriptome in IPF patients varies from normal individuals by documenting that 1428 and 2790 genes were differentially regulated in mild versus severe IPF, respectively, when compared with controls. Extending this observation, Herazo-Maya et al. [7] showed that gene expression patterns in PBMCs predict outcome in IPF patients. In that study, decreased expression of CD28, ICOS, LCK and ITK was a stronger outcome predictor than clinical data alone. 
a)
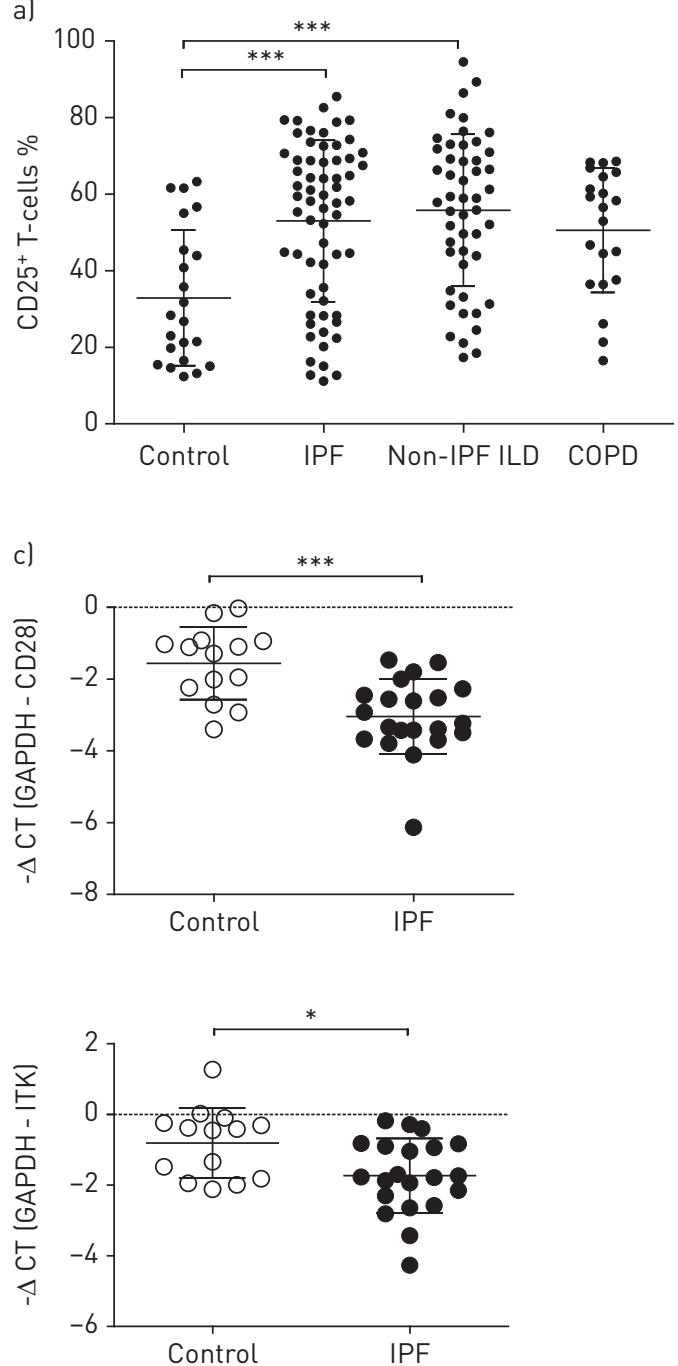
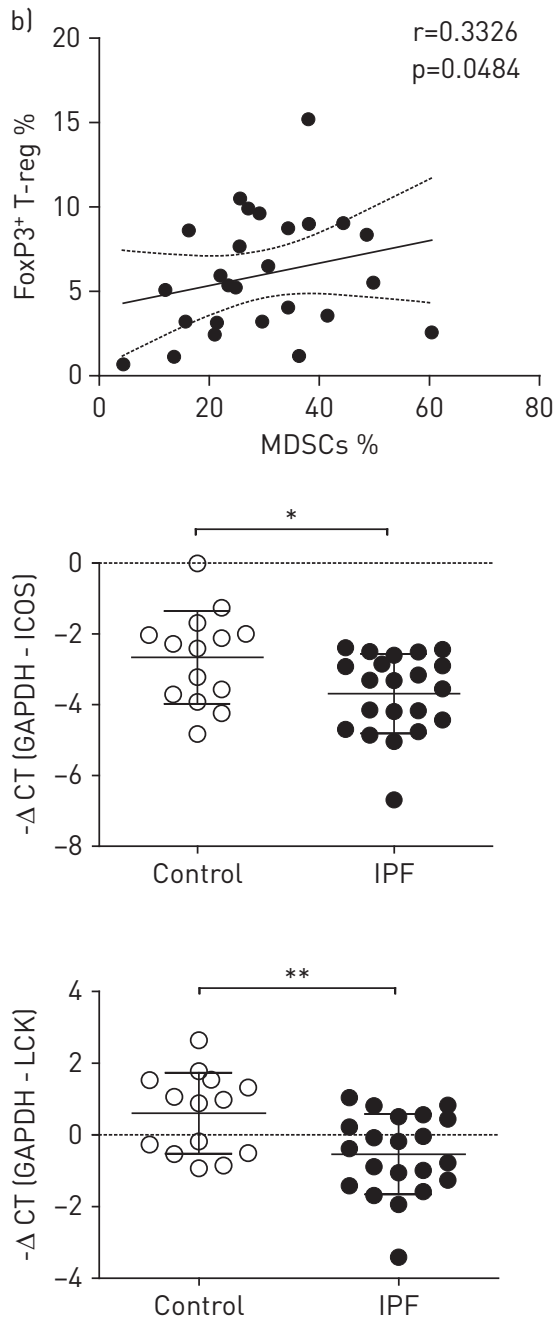

FIGURE $6 \mathrm{CD}^{2} 5^{+} \mathrm{T}$-cells, FoxP3 ${ }^{+}$regulatory T-cells (T-reg) and co-stimulatory T-cell signals are dysregulated in idiopathic pulmonary fibrosis (IPF). a) Scatter-plot diagrams from flow cytometry analysis of CD25+ T-cells las \% gated $\mathrm{CD}^{+} \mathrm{CD4}^{+}$) in 22 healthy controls, 69 IPF, 56 non-IPF interstitial lung disease (ILD) and 23 chronic obstructive pulmonary disease (COPD) patients. For statistical analysis, one-way ANOVA was used with the non-parametric Kruskal-Wallis test, followed by Dunnett's multiple comparison test. b) Correlation of \% FoxP3 ${ }^{+}$ T-reg cells (as \% gated $\mathrm{CD}_{4}^{+} \mathrm{CD}^{+} 5^{+}$) and myeloid-derived suppressor cells (MDSC). p-values were determined by t-distribution for Pearson correlation. c) qPCR analysis of CD28, ICOS, ITK and LCK in peripheral blood mononuclear cell pellets of healthy controls $(n=14)$ and IPF patients $(n=21)$. Non-parametric two-tailed MannWhitney U-test was used for statistical analysis. ${ }^{*}: p<0.05 ;{ }^{* *}: p<0.01 ;{ }^{* * *}: p<0.001$.

Although these data support an important role for immunosuppression in IPF by elucidating the role of T-reg cells, another major innate immunosuppressive cell type, MDSC, has not been investigated at all in lung fibrosis. In the lung, the presence of MDSCs was initially described in advanced nonsmall cell lung cancer [34], where their presence has been widely explored, both clinically [17] and mechanistically [35]. In cystic fibrosis, MDSCs have been associated with Pseudomonas aeruginosa infections, demonstrating that this pathogen induced MDSC generation via flagellin [19]. In TB, increased MDSC numbers are described to suppress T-cell functions [18]. To this extent, KNAUL et al. [36] unravelled a complex role of MDSCs in murine TB. MDSCs accumulated in TB lungs, acted as phagocytes and provided a cellular shelter for mycobacteria, which then suppressed T-cell responses and led to increased TB lethality. In pulmonary hypertension, MDSCs are increased and their levels correlated with increased mean pulmonary artery pressure [37]. In COPD, recent work demonstrated an effector T-cell dysfunction composed by T-reg cells, MDSC and PD-1 exhausted effector T-cells [20].

Of note, we did not observe a significant increase in MDSC numbers in COPD patients in our study. This difference could be due to the fact that KaLATHIL et al. [20] investigated an older and more advanced 
a

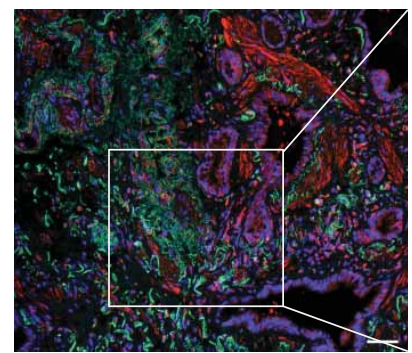

b)

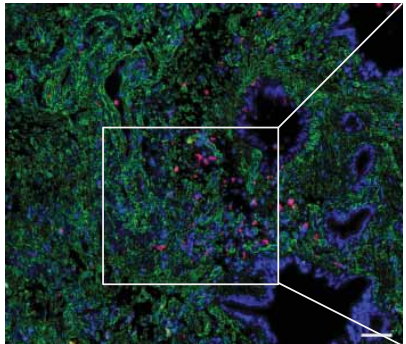

c)

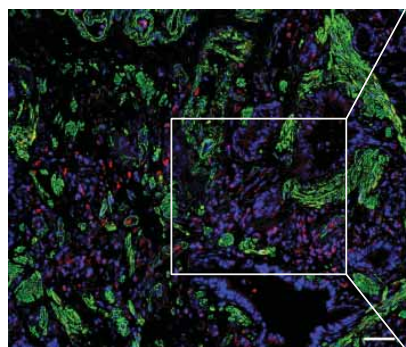

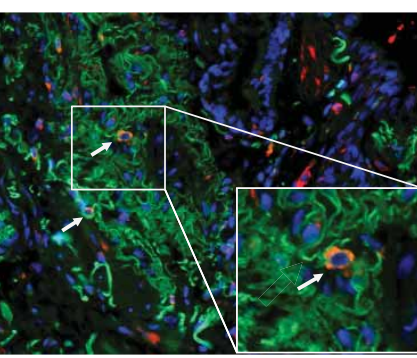
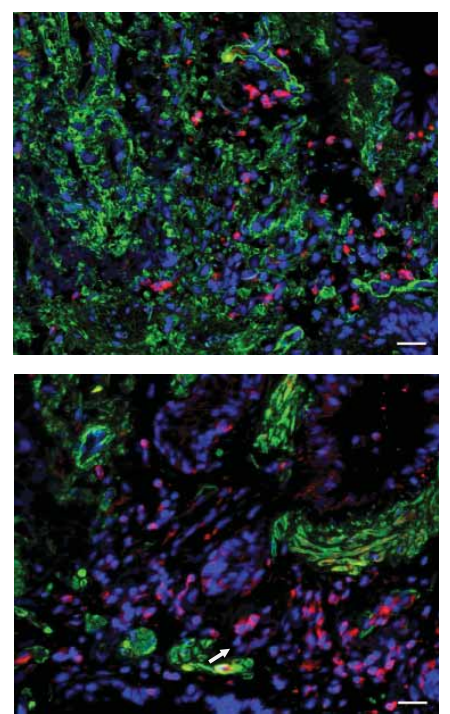
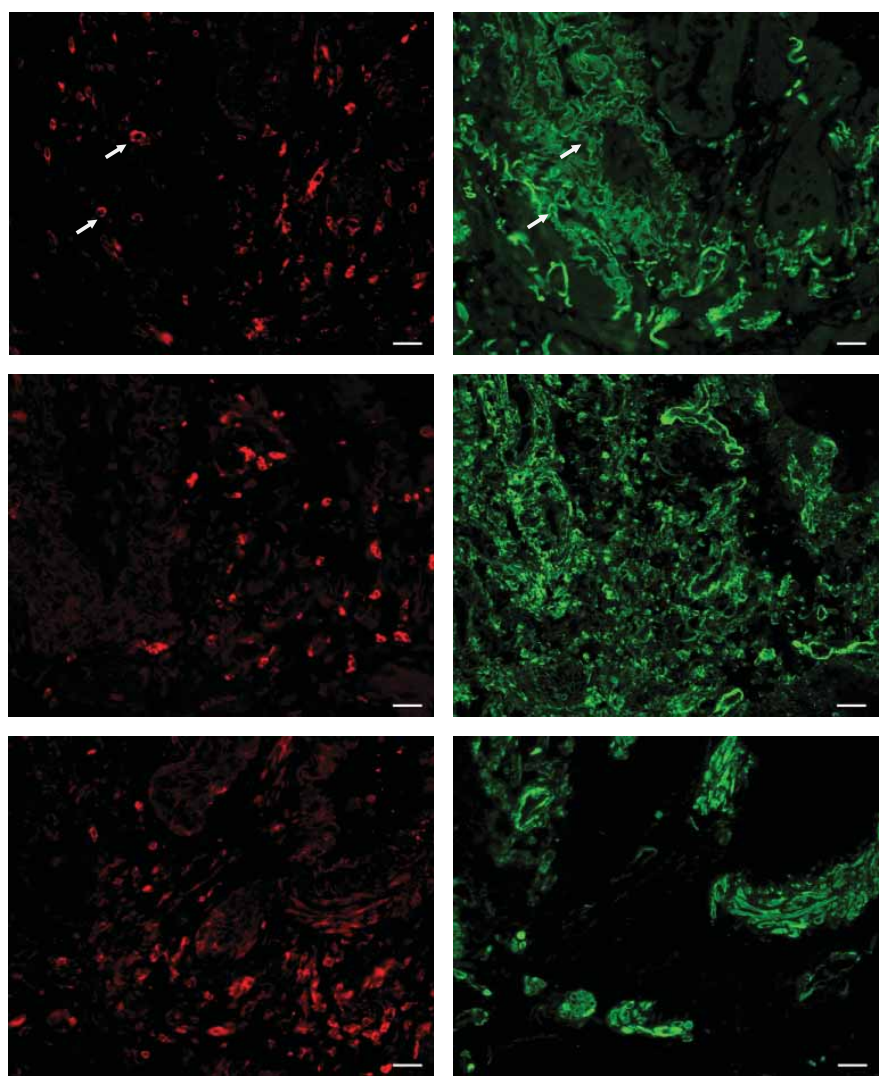

FIGURE $7 \mathrm{CD} 3^{+} \mathrm{CD} 11 \mathrm{~b}^{+}$cells are present in fibrotic areas of idiopathic pulmonary fibrosis (IPF) lungs. Representative immunofluorescence of sequential cuts from paraffin sections of IPF lungs are shown stained for: a) CD33 (red) and CD11b (green), b) CD11b (red) and collagen 1 (green), and c) CD33 (red) and $\alpha$-SMA (green). For all, nuclei were counterstained with DAPI (blue). Lower magnifications (left-hand panel) are presented at $10 \times($ scale bar $=50 \mu \mathrm{m})$. White squares represent higher magnifications (scale bar $=20 \mu \mathrm{m}$ ), depicted as merged images and single channel images for the red and green channel. $C D 33^{+} \mathrm{CD} 11 \mathrm{~b}^{+}$cells are indicated with a white arrow. Sections are representative stains of two IPF patients and one hypersensitivity pneumonitis patient.

COPD population, with worse baseline lung function compared to our cohort. It is also critical to highlight that, due to the diverse strategies to phenotypically define MDSC, it is difficult to compare absolute cell numbers across diseases.

Granulocytic MDSCs are described to be the predominant MDSC subtype in malignancies of several organ systems. Surprisingly, our analysis of MDSC subtypes in IPF revealed that monocytic MDSCs are the predominant subtype in IPF. Peyvandi et al. [38] recently demonstrated that modulation of the Fas-FasL pathway did not increase overall MDSC abundance; however, it skewed the MDSC subtype towards a highly suppressive monocytic MDSC subtype. It simultaneously increased the number of tumour-associated macrophages and T-reg cells, and increased tumour growth with decreased survival in a mouse model of lung cancer [38]. We believe that further studies are necessary to clarify the differential contribution of MDSC subtypes to lung fibrosis.

Previous reports have shown that ageing affects MDSC abundance, influencing the progression of age-related pathologies [39]. The age of our IPF population was significantly higher when compared with controls (mean age 68.2 versus 55.4 years). However, it is important to note the mean age for the young adult population in the study mentioned above was 32 years, i.e. 20 years younger than our control group. Therefore, we consider that the effect of age only for our analysis is minimal.

In repeated visits in our study we demonstrated that increased MDSC numbers over time significantly correlated with the decline in VCmax. This was observed in a greater extent in IPF patients than in non-IPF ILD or COPD. We reason for this may be due to the fact that IPF exhibits different disease pathogenesis than non-IPF ILD. Also non-IPF ILD exhibits more variability in its natural history and treatment responsiveness, which may influence data interpretation.

One of the critical roles of MDSCs is their ability to suppress immune cell function, especially by the induction of arginase, COX2, ROS, inducible NOS secretion of transforming growth factor- $\beta$ and/or 
induction of T-reg cells [26], all of which are pro-fibrotic players [40]. At the tumour site, MDSCs can differentiate into tumour-associated macrophages [27, 41] or regulatory dendritic cells [42]. Furthermore, in mouse models of metastatic melanoma and breast cancer, MDSCs were shown to differentiate into fibrocytes, in a KLF4-dependent manner, to support the establishment of lung metastasis [43]. In a murine model of renal fibrosis, fibrocytes generated from a subpopulation MDSC under control of CD4 ${ }^{+}$ cells contributed to renal deposition of collagen type I [44]. A population of circulating MDSC-like fibrocytes was initially reported in metastatic cancer patients by ZHANG et al. [45], which showed expression of $\alpha$-SMA, collagen $\mathrm{I} / \mathrm{V}$ and mediation of angiogenesis. Importantly, circulating fibrocytes numbers are increased in IPF [46] and non-IPF ILD [47], and have been associated with poor prognosis. It is therefore important to define the overlap between FACS-defined MDSC and fibrocytes in future prospective studies.

Ample evidence supports the use of MDSCs as biomarkers for clinical outcomes in cancer patients, specifically when assessing tumour progression and response to therapy [48]. High percentages of circulating MDSCs have been shown to predict resistance to anticancer therapies and shorter survival [49]. Further evidence supporting the promotion of tumour growth, differentiation and metastasis by MDSCs is growing. In diffuse large B-cell lymphoma [50] and melanoma [51], MDSCs are an independent prognostic factor. In head and neck squamous cell carcinoma, MDSC abundance correlated with cancer stage [52]. In gastric [53] and renal carcinoma [54], MDSC inhibited T-cell proliferation and correlated with later stage and shorter overall survival. In breast cancer, MDSCs suppress antitumor immune responses, and correlate with lymph node metastasis [55]. In addition, sufficient evidence from preclinical models and clinical testing of multiple cancers types, such as melanoma [56], breast cancer [57], nonsmall cell lung cancer [58] or metastatic kidney cancer [59], demonstrated that targeting and decreasing MDSC abundance increased the tumour's sensitivity to chemotherapy. Accordingly, novel therapeutic strategies in the above-mentioned diseases aim to eliminate, deactivate or skew MDSC number and/or function [26], and it is probably suitable to explore these interventions in IPF.

IPF has been considered as a cancer-like disorder, due to the activation of common pathogenic pathways and shared mechanisms (e.g. expansion of tissue-resident cells, activation of pro-proliferative signalling pathways) that are finally reflected in poor responses to medical treatment and clinical prognosis. Importantly, MDSC abundance in IPF and many cancer types might further support the available data in overlapping mechanism between these two conditions.

In conclusion, our study demonstrates, for the first time, the accumulation of MDSCs in peripheral blood and tissue of IPF patients. MDSCs inversely correlated with lung function, reflecting more advanced disease in IPF patients with high MDSC. These findings might explain dysregulated T-cell responses in IPF. Elevated MDSCs might cause a blunted immune response, which also might be an explanatory link for the increased incidence and burden of lung cancer in IPF. Controlling the expansion and accumulation of MDSCs or blocking their suppressive functions represents promising novel approaches to be used as a therapeutic strategy in IPF patients.

\section{Acknowledgements}

We thank Daniela Dietel (Comprehensive Pneumology Center, Ludwig-Maximilians-University, University Hospital Grosshadern, and Helmholtz Zentrum München, Member of the German Center for Lung Research, Munich, Germany) for excellent technical assistance, and the Helmholtz association for supporting this work.

The authors' contributions were as follows. Conception and design: I.E. Fernandez and O. Eickelberg; experimental work, analysis and interpretation: I.E. Fernandez, F.R. Greiffo, M. Frankenberger, J. Bandres, K. Heinzelmann, R. Hatz, C. Neurohr, D. Hartl, J. Behr and O. Eickelberg; drafting the manuscript and intellectual content: I.E. Fernandez and O. Eickelberg.

\section{References}

$1 \quad$ King TE Jr, Pardo A, Selman M. Idiopathic pulmonary fibrosis. Lancet 2011; 378: 1949-1961.

2 Wuyts WA, Antoniou KM, Borensztajn K, et al. Combination therapy: the future of management for idiopathic pulmonary fibrosis? Lancet Respir Med 2014; 2: 933-942.

3 Zoz DF, Lawson WE, Blackwell TS. Idiopathic pulmonary fibrosis: a disorder of epithelial cell dysfunction. Am J Med Sci 2011; 341: 435-438.

4 Fernandez IE, Eickelberg O. New cellular and molecular mechanisms of lung injury and fibrosis in idiopathic pulmonary fibrosis. Lancet 2012; 380: 680-688.

5 Reilkoff RA, Peng H, Murray LA, et al. Semaphorin 7a+ regulatory T-cells are associated with progressive idiopathic pulmonary fibrosis and are implicated in transforming growth factor-betal-induced pulmonary fibrosis. Am J Respir Crit Care Med 2013; 187: 180-188.

6 Gilani SR, Vuga LJ, Lindell KO, et al. CD28 down-regulation on circulating CD4 T-cells is associated with poor prognoses of patients with idiopathic pulmonary fibrosis. PloS One 2010; 5: e8959.

7 Herazo-Maya JD, Noth I, Duncan SR, et al. Peripheral blood mononuclear cell gene expression profiles predict poor outcome in idiopathic pulmonary fibrosis. Sci Transl Med 2013; 5: $205 \mathrm{ra} 136$.

8 Kotsianidis I, Nakou E, Bouchliou I, et al. Global impairment of CD4+CD25+FOXP3+ regulatory T-cells in idiopathic pulmonary fibrosis. Am J Respir Crit Care Med 2009; 179: 1121-1130. 
9 Wynn TA. Integrating mechanisms of pulmonary fibrosis. J Exp Med 2011; 208: 1339-1350.

10 Moore BB, Fry C, Zhou Y, et al. Inflammatory leukocyte phenotypes correlate with disease progression in idiopathic pulmonary fibrosis. Front Med 2014; 1: pii00056.

11 Lindau D, Gielen P, Kroesen M, et al. The immunosuppressive tumour network: myeloid-derived suppressor cells, regulatory T-cells and natural killer T-cells. Immunology 2013; 138: 105-115.

12 Talmadge JE, Gabrilovich DI. History of myeloid-derived suppressor cells. Nat Rev Cancer 2013; 13: 739-752.

13 Damuzzo V, Pinton L, Desantis G, et al. Complexity and challenges in defining myeloid-derived suppressor cells. Cytom Part B Clin Cytom 2015; 88: 77-91.

14 Lees JR, Azimzadeh AM, Bromberg JS. Myeloid derived suppressor cells in transplantation. Curr Opin Immunol 2011; 23: 692-697.

15 Vollbrecht T, Stirner R, Tufman A, et al. Chronic progressive HIV-1 infection is associated with elevated levels of myeloid-derived suppressor cells. AIDS 2012; 26: F31-F37.

16 Li Y, Tu Z, Qian S, et al. Myeloid-derived suppressor cells as a potential therapy for experimental autoimmune myasthenia gravis. J Immunol 2014; 193: 2127-2134.

17 Feng $\mathrm{PH}$, Lee $\mathrm{KY}$, Chang YL, et al. $\mathrm{CD} 14^{+} \mathrm{S} 100 \mathrm{~A} 9^{+}$monocytic myeloid-derived suppressor cells and their clinical relevance in non-small cell lung cancer. Am J Respir Crit Care Med 2012; 186: 1025-1036.

18 du Plessis N, Loebenberg L, Kriel M, et al. Increased frequency of myeloid-derived suppressor cells during active tuberculosis and after recent Mycobacterium tuberculosis infection suppresses T-cell function. Am J Respir Crit Care Med 2013; 188: 724-732.

19 Rieber N, Brand A, Hector A, et al. Flagellin induces myeloid-derived suppressor cells: implications for Pseudomonas aeruginosa infection in cystic fibrosis lung disease. J Immunol 2013; 190: 1276-1284.

20 Kalathil SG, Lugade AA, Pradhan V, et al. T-regulatory cells and programmed death 1+ T-cells contribute to effector T-cell dysfunction in patients with chronic obstructive pulmonary disease. Am J Respir Crit Care Med 2014; 190: 40-50.

21 Kolahian S, Öz HH, Zhou B, et al. The emerging role of myeloid-derived suppressor cells in lung diseases. Eur Respir J 2016; 47: 967-977.

22 Raghu G, Rochwerg B, Zhang Y, et al. An Official ATS/ERS/JRS/ALAT Clinical Practice Guideline: Treatment of Idiopathic Pulmonary Fibrosis. an update of the 2011 Clinical Practice Guideline Am J Respir Crit Care Med 2015; 192: e3-e19.

23 Maecker HT, McCoy JP, Nussenblatt R. Standardizing immunophenotyping for the Human Immunology Project. Nat Rev Immunol 2012; 12: 191-200.

24 Heimbeck I, Hofer TP, Eder C, et al. Standardized single-platform assay for human monocyte subpopulations: lower CD14+CD16++ monocytes in females. Cytom Part A 2010; 77: 823-830.

25 Kostlin N, Kugel H, Spring B, et al. Granulocytic myeloid derived suppressor cells expand in human pregnancy and modulate T-cell responses. Eur J Immunol 2014; 44: 2582-2591.

26 Marvel D, Gabrilovich DI. Myeloid-derived suppressor cells in the tumor microenvironment: expect the unexpected. J Clin Invest 2015; 125: 3356-3364.

27 Franklin RA, Liao W, Sarkar A, et al. The cellular and molecular origin of tumor-associated macrophages. Science 2014; 344: 921-925.

28 Raghu G, Anstrom KJ, King TE Jr, et al. Prednisone, azathioprine, and $N$-acetylcysteine for pulmonary fibrosis. N Engl J Med 2012; 366: 1968-1977.

29 Lo Re S, Lison D, Huaux F. CD4+ T lymphocytes in lung fibrosis: diverse subsets, diverse functions. J Leukoc Biol 2013; 93: 499-510.

30 Marchal-Somme J, Uzunhan Y, Marchand-Adam S, et al. Cutting edge: nonproliferating mature immune cells form a novel type of organized lymphoid structure in idiopathic pulmonary fibrosis. J Immunol 2006; 176: 5735-5739.

31 Mack DG, Lanham AM, Palmer BE, et al. CD27 expression on CD4+ T-cells differentiates effector from regulatory T-cell subsets in the lung. J Immunol 2009; 182: 7317-7324.

32 Liu F, Liu J, Weng D, et al. CD4+CD25+Foxp3+ regulatory T-cells depletion may attenuate the development of silica-induced lung fibrosis in mice. PLoS One 2010; 5: e15404.

33 Yang IV, Luna LG, Cotter J, et al. The peripheral blood transcriptome identifies the presence and extent of disease in idiopathic pulmonary fibrosis. PLoS One 2012; 7: e37708.

34 Srivastava MK, Bosch JJ, Thompson JA, et al. Lung cancer patients' CD4 ${ }^{+}$T-cells are activated in vitro by MHC II cell-based vaccines despite the presence of myeloid-derived suppressor cells. Cancer Immunol Immunother 2008; 57: 1493-1504.

35 Zhang Y, Liu Q, Zhang M, et al. Fas signal promotes lung cancer growth by recruiting myeloid-derived suppressor cells via cancer cell-derived PGE2. J Immunol 2009; 182: 3801-3808.

36 Knaul JK, Jorg S, Oberbeck-Mueller D, et al. Lung-residing myeloid-derived suppressors display dual functionality in murine pulmonary tuberculosis. Am J Respir Crit Care Med 2014; 190: 1053-1066.

37 Yeager ME, Nguyen CM, Belchenko DD, et al. Circulating myeloid-derived suppressor cells are increased and activated in pulmonary hypertension. Chest 2012; 141: 944-952.

38 Peyvandi S, Buart S, Samah B, et al. Fas ligand deficiency impairs tumor immunity by promoting an accumulation of monocytic myeloid-derived suppressor cells. Cancer Res 2015; 75: 4292-4301.

39 Verschoor CP, Johnstone J, Millar J, et al. Blood CD33 ${ }^{+}$HLA-DR ${ }^{-}$myeloid-derived suppressor cells are increased with age and a history of cancer. J Leukoc Biol 2013; 93: 633-637.

40 Fernandez IE, Eickelberg O. The impact of TGF- $\beta$ on lung fibrosis: from targeting to biomarkers. Proc Am Thorac Soc 2012; 9: 111-116

41 Corzo CA, Condamine T, Lu L, et al. HIF-1 $\alpha$ regulates function and differentiation of myeloid-derived suppressor cells in the tumor microenvironment. J Exp Med 2010; 207: 2439-2453.

42 Zhong H, Gutkin DW, Han B, et al. Origin and pharmacological modulation of tumor-associated regulatory dendritic cells. Int J Cancer 2014; 134: 2633-2645.

43 Shi Y, Ou L, Han S, et al. Deficiency of Kruppel-like factor KLF4 in myeloid-derived suppressor cells inhibits tumor pulmonary metastasis in mice accompanied by decreased fibrocytes. Oncogenesis 2014; 3: e129.

44 Niedermeier M, Reich B, Rodriguez Gomez M, et al. CD4+ T-cells control the differentiation of Gr1+ monocytes into fibrocytes. Proc Natl Acad Sci USA 2009; 106: 17892-17897. 
Zhang H, Maric I, DiPrima MJ, et al. Fibrocytes represent a novel MDSC subset circulating in patients with metastatic cancer. Blood 2013; 122: 1105-1113.

46 Moeller A, Gilpin SE, Ask K, et al. Circulating fibrocytes are an indicator of poor prognosis in idiopathic pulmonary fibrosis. Am J Respir Crit Care Med 2009; 179: 588-594.

47 Garcia de Alba C, Buendia-Roldan I, Salgado A, et al. Fibrocytes contribute to inflammation and fibrosis in chronic hypersensitivity pneumonitis through paracrine effects. Am J Respir Crit Care Med 2015; 191: 427-436.

48 Walter S, Weinschenk T, Stenzl A, et al. Multipeptide immune response to cancer vaccine IMA901 after single-dose cyclophosphamide associates with longer patient survival. Nat Med 2012; 18: 1254-1261.

49 Wang Z, Zhang Y, Liu Y, et al. Association of myeloid-derived suppressor cells and efficacy of cytokine-induced killer cell immunotherapy in metastatic renal cell carcinoma patients. J Immunother 2014; 37: 43-50.

50 Tadmor T, Fell R, Polliack A, et al. Absolute monocytosis at diagnosis correlates with survival in diffuse large B-cell lymphoma-possible link with monocytic myeloid-derived suppressor cells. Hematol Oncol 2013; 31: 65-71.

51 Weide B, Martens A, Zelba H, et al. Myeloid-derived suppressor cells predict survival of patients with advanced melanoma: comparison with regulatory T-cells and NY-ESO-1- or melan-A-specific T-cells. Clin Cancer Res 2014; 20: $1601-1609$

52 Vasquez-Dunddel D, Pan F, Zeng Q, et al. STAT3 regulates arginase-I in myeloid-derived suppressor cells from cancer patients. J Clin Invest 2013; 123: 1580-1589.

53 Rodriguez PC, Ernstoff MS, Hernandez C, et al. Arginase I-producing myeloid-derived suppressor cells in renal cell carcinoma are a subpopulation of activated granulocytes. Cancer Res 2009; 69: 1553-1560.

54 Wang L, Chang EW, Wong SC, et al. Increased myeloid-derived suppressor cells in gastric cancer correlate with cancer stage and plasma S100A8/A9 proinflammatory proteins. J Immunol 2013; 190: 794-804.

$55 \mathrm{Yu}$ J, Du W, Yan F, et al. Myeloid-derived suppressor cells suppress antitumor immune responses through IDO expression and correlate with lymph node metastasis in patients with breast cancer. J Immunol 2013; 190: 3783-3797.

56 Schilling B, Sucker A, Griewank K, et al. Vemurafenib reverses immunosuppression by myeloid derived suppressor cells. Int J Cancer 2013; 133: 1653-1663.

57 Verma C, Eremin JM, Robins A, et al. Abnormal T-regulatory cells (Tregs: FOXP3+, CTLA-4+), myeloid-derived suppressor cells (MDSCs: monocytic, granulocytic) and polarised T-helper cell profiles (Th1, Th2, Th17) in women with large and locally advanced breast cancers undergoing neoadjuvant chemotherapy (NAC) and surgery: failure of abolition of abnormal treg profile with treatment and correlation of treg levels with pathological response to NAC. J Transl Med 2013; 11: 16

58 Iclozan C, Antonia S, Chiappori A, et al. Therapeutic regulation of myeloid-derived suppressor cells and immune response to cancer vaccine in patients with extensive stage small cell lung cancer. Cancer Immunol Immunother 2013; 62: 909-918.

59 Mirza N, Fishman M, Fricke I, et al. All-trans-retinoic acid improves differentiation of myeloid cells and immune response in cancer patients. Cancer Res 2006; 66: 9299-9307. 